\title{
Histopathological Interpretation Of Colonic Mucosal Biopsies With Clinical Correlation: A Study In A Tertiary Care Hospital Kerala
}

\author{
Abilash S C ${ }^{1 *}$ and Shreelakshmidevi $\mathrm{S}^{2}$ \\ 'Pathology, DM Wayanad Institute Of medical sciences, Naseera Nagar, Meppadi, Wayanad, Kerala, India \\ ${ }^{2}$ Pharmacology, DM Wayanad Institute Of medical sciences, Naseera Nagar, Meppadi, Wayanad, Kerala, India
}

\section{ABSTRACT}

Background: Colon is the most common site for various diseases. Diseases affecting the colon may cause abdominal pain, constipation, diarrhea and bleeding per rectum. Colonoscopy is an endoscopic examination of the colon with a flexible optic fibers, this method allows visual examination of colonic mucosa and provides opportunity for mucosal biopsies. This study was carried out to study and correlate histopathological spectrum of colonic mucosal biopsies with clinical findings.

Methods: This two years study was conducted during the period of April 2015 to March 2017. 250 colonoscopic biopsies were included in the study. All biopsies were fixed in formalin, processed as per routine histopathology processing, stained with Hematoxylin \& Eosin stains and studied.

Result: Out of 250 colonoscopic biopsies, 152 were non-neoplastic and 98 were neoplastic. Non neoplastic lesions were found to affect the colon most commonly. Most of the cases with non-neoplastic lesions presented with colicky abdominal pain, diarrhea and constipation. Among neoplastic lesions, 44 cases were benign and 54 cases were malignant. Majority of cases with neoplastic lesions presented with bleeding per rectum and constipation.

Conclusion: Non neoplastic lesions were found to affect the colon most commonly. This study emphasize the increase in incidence of ulcerative colitis and colorectal carcinomas. Histopathological interpretation on colonic mucosal biopsies has taken a cornerstone in the diagnosis and management of patients with colonic lesions.

Keywords: Colonoscopy, Colitis, Adenoma, Adenocarcinoma

\section{Introduction}

Colon is the primary site for various non neoplastic and neoplastic diseases. The spectrum of colonic lesions range from congenital diseases, Infections, Inflammatory conditions, Vascular diseases, Polyps and Colorectal tumours. Colorectal carcinoma is one of the leading cause of morbidity and mortality with an overall cancer incidence rate of $9 \% .^{[1,2]}$

Development of flexible fibreoptic sigmoidoscopy and colonoscopy revolutionized the diagnosis and management of colorectal diseases, for the reason that the procedure is safe with no serious complications. Application of therapeutic colonoscopy like colonoscopic polypectomy has replaced the open surgical procedure to a great extent. ${ }^{[3]}$

In developing countries like India, where tuberculosis and infective colitis are more prevalent, the diagnosis of Inflammatory Bowel disease is a great challenge. Colonic mucosal biopsies procured from colonoscopy plays a crucial role in specific diagnosis of patients with Inflammatory Bowel disease ${ }^{[4,5]}$ and early detection of colonic epithelial tumours. $^{[6]}$ Histopathological interpretation of colonic mucosal biopsies when correlated with clinical findings help in definitive diagnosis and early treatment of patients with colonic lesions.

The current study was carried out with an aim to study histopathological pattern of colonic mucosal biopsies and correlate them with clinical findings.

\section{Materials and Methods}

The present study was a two year retrospective study, conducted in the department of pathology DM Wayand Institute of Medical Sciences, Kerala during the period from April 2015 to March 2017. 250 cases presented with symptoms were selected for the study. Patient's age, sex, presenting complaints, relevant past history were noted and colonoscopy was performed.

All biopsies received were immediately fixed in $10 \%$ formalin. The tissue bits were counted, measured and processed completely as per routine histopathology processing. From each paraffin block 3 to 5 micron thick 
section were prepared by using rotary microtome. All slides were then stained with Hematoxylin \& Eosin stains. Special stains like Giemsa and Periodic Acid Schiff were done wherever necessary. Detailed study of all the slides were done under light microscope by the pathologists and diagnosis was furnished.

The study was approved and permitted by Institutional Ethical Committee.

\section{Result}

A total of 250 colonoscopic biopsies were examined during the stipulated period of time. Out of 250 cases, 167 were males and 83 were females. Male female ratio was found to be 2.1:1. Age of patients ranged from 20 to 89 years. Majority of the cases 121 (48.4\%) were presented with colicky abdominal pain and loose stools, followed by bleeding Per Rectum in 77 cases (30.8\%), 34 cases $(13.6 \%)$ presented with diarrhea and constipation in 18 cases $(7.2 \%)$

Among all the colonic biopsies, histologically 152 cases (60.8\%) were diagnosed as non-neoplastic lesions and 98 cases $(39.2 \%)$ were diagnosed as neoplastic lesions. Out of 152 non-neoplastic lesions, Non Specific colitis was found to be the commonest lesion in 71 cases $(46.71 \%)$ followed by ulcerative colitis in 38 cases $(25 \%)$. Non neoplastic lesions were found in all age groups with male:female ratio of 2.8:1. [Table 1]

Among 98 neoplastic lesions, Benign lesions were in seen in 44 cases $(44.9 \%)$ and Malignant lesions were observed in 54 cases $(55.1 \%)$. All benign lesions were diagnosed as colonic adenomas and all the malignant lesions were diagnosed as adenocarcinomas. Colonic Adenomas were seen between 50 to 80 years of age group with a male to female ratio of 1.6:1 showing a slight male preponderance. Adenocarcinomas were common in $5^{\text {th }}$ to $7^{\text {th }}$ decade with a male female ratio of 1.1:1. The most common histological subtype diagnosed was well differentiated adenocarcinoma.
Histopathology of Non-Neoplastic Lesions: In the present study, non-specific colitis was observed in 71 cases, characterized by unremarkable colonic mucosal glands and expansion of lamina propria by lymphoplasmcytic infiltrate with no cryptitis or crypt abscess. Ulcerative colitis was seen in 38 cases, characterized by cryptitis, crypt abscess, crypt distortion, variation in inter crypt distance, basal plasmacytosis and mixed inflammatory cell infiltrate in lamina propria[Fig 1]. 3 cases of Chron's disease showed well-defined non-caseating granulomas and transmural lymphoplasmacytic infiltrate. Hyperplastic polyp was seen in 12 cases, characterized by elongated glands and crypts with serrated appearance. 5 cases of inflammatory polyp showed infiltration of lamina propria by inflammatory cells with focal mucosal erosions and hemorrhage. Solitary Rectal Ulcer was seen in 5 cases, characterized by cystic dilatation of glands with fibromuscular hyperplasia.

Histopathology of Neoplastic Lesions: Among 44 cases of colonic adenomas diagnosed in our study, tubular adenoma was seen in 38 cases, characterized by increased number of tubular glands and these glands showed nuclear stratification with hyperchromatic nuclei limited to the lower one third of glandular epithelium [Fig 2]. Remaining 6 cases showed tubulovillous adenoma, characterized by tubular and elongated glands with nuclear features same as that of tubular adenoma. High grade dysplasia was observed in 6 cases of adenomatous polyp [Fig 3].

Among 54 cases of adenocarcinomas, well differentiated adenocarcinomas were seen in 29 cases, characterized by well-formed malignant glands infiltrating into submucosa [Fig 4]. 21 cases showed moderately differentiated adenocarcinomas, characterized by ill formed malignant glands with poor outlines. Poorly differentiated carcinomas were observed in 3 cases, characterized by malignant cells in groups or in cords with no glandular structures. Single case showed Signet ring carcinoma characterized by signet shaped malignant cells infiltrating in to the submucosa [Fig 5].

Table 1: Distribution of Non-neoplastic lesions.

\begin{tabular}{|l|l|c|}
\hline S.No & Lesions & Number of cases (Percentage) \\
\hline 1 & Non-specific colitis & $71(46.71 \%)$ \\
\hline 2 & Infective colitis & $06(3.95 \%)$ \\
\hline 3 & Ulcerative colitis & $38(25 \%)$ \\
\hline 4 & Chron's Disease & $03(1.97 \%)$ \\
\hline 5 & Hyperplastic Polyp & $12(7.89 \%)$ \\
\hline 6 & Inflammatory Polyp & $05(3.29 \%)$ \\
\hline 7 & Solitary Rectal Ulcer & $05(3.29 \%)$ \\
\hline 8 & Melanosis coli & $04(2.63 \%)$ \\
\hline 9 & Pseudomembranous colitis & $01(0.66 \%)$ \\
\hline 10 & Tuberculosis & $01(0.66 \%)$ \\
\hline 11 & No significant pathology & $06(3.95 \%)$ \\
\hline & Total & $\mathbf{1 5 2 ( 1 0 0 \% )}$ \\
\hline
\end{tabular}




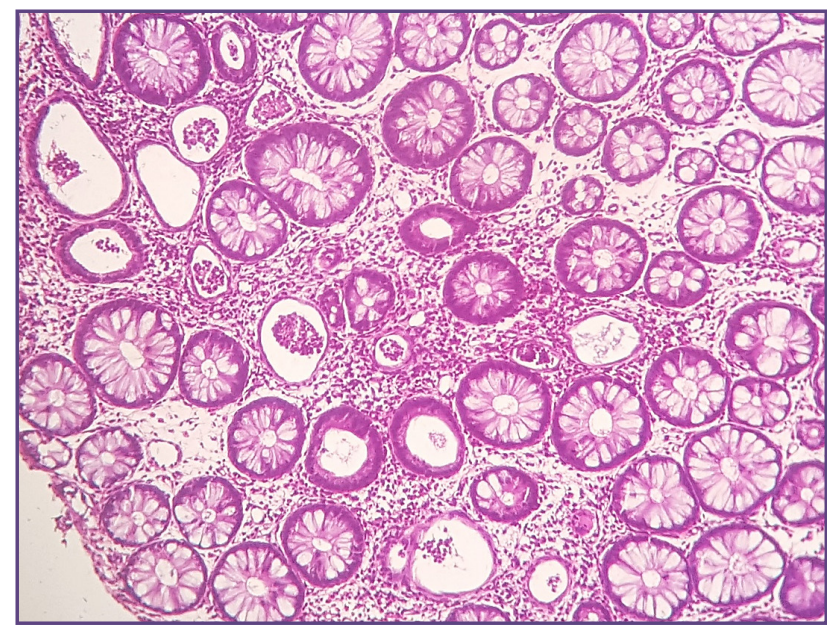

Fig. 1: Photomicrograph of Ulcerative Colitis showing cryptitis, crypt abscess and crypt distortion (H\&E; 4X).

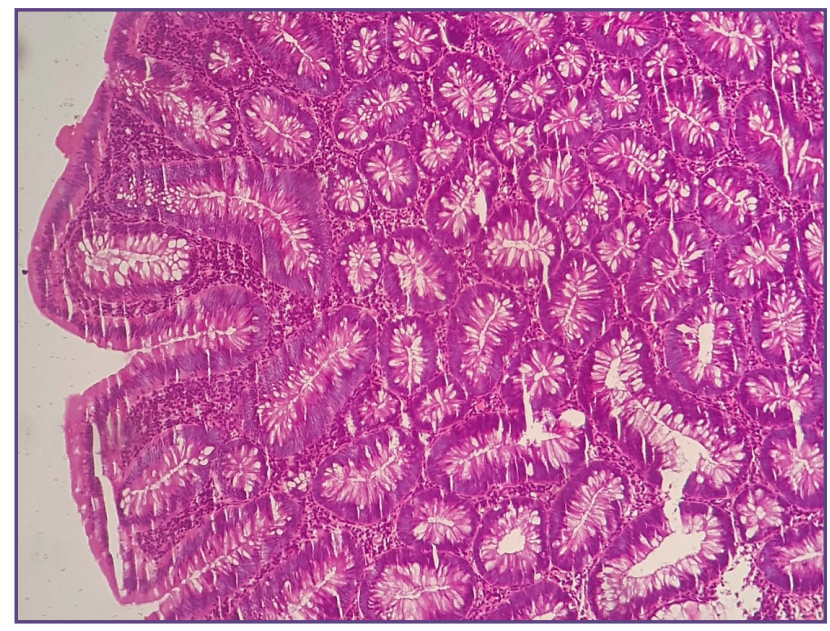

Fig. 3: Photomicrograph of Tubular Adenoma with High Grade Dysplasia (H\&E; 10X).

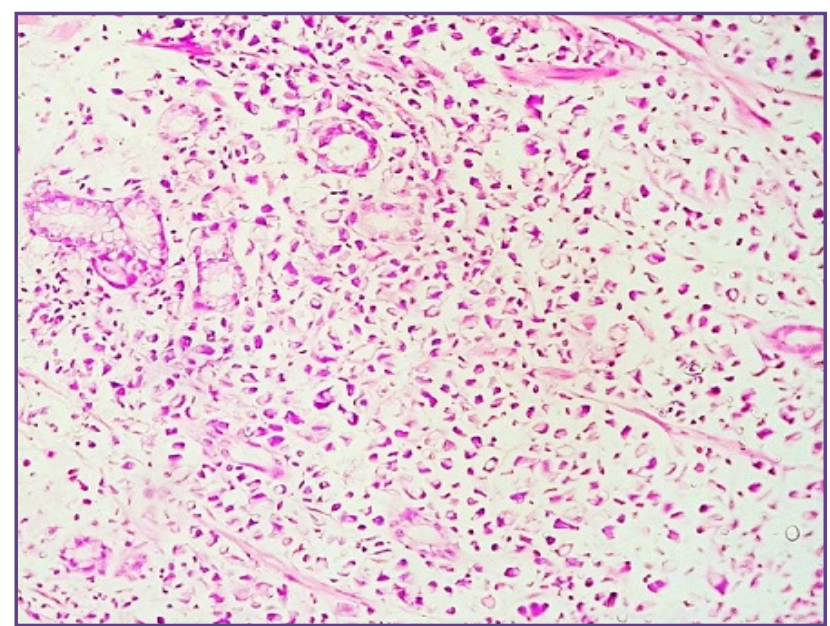

Fig. 5: Photomicrograph of Signet Ring Carcinoma (H\&E; 4X).

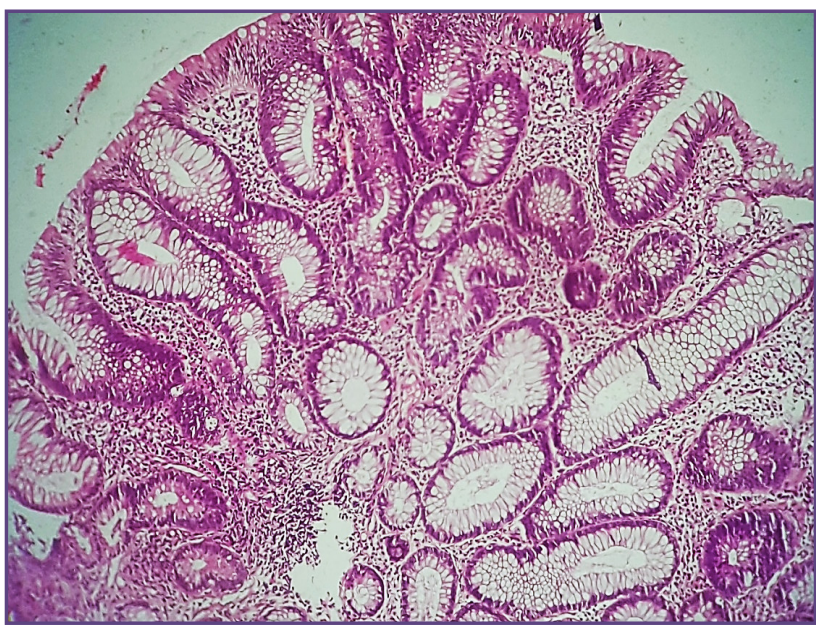

Fig. 2: Photomicrograph of Tubular Adenoma without High Grade Dysplasia (H\&E; 10X).

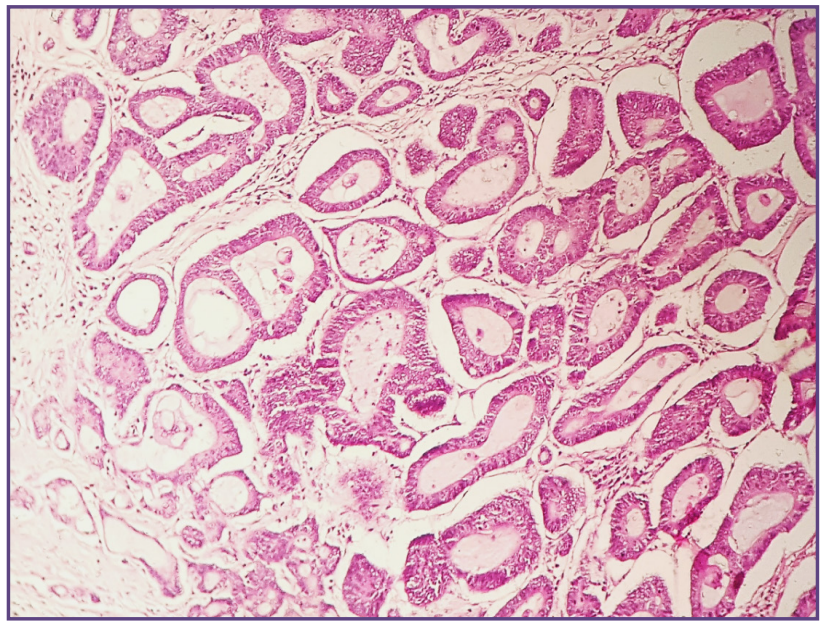

Fig. 4: Photomicrograph of Well Differentiated Adenocarcinoma (H\&E; 10X).

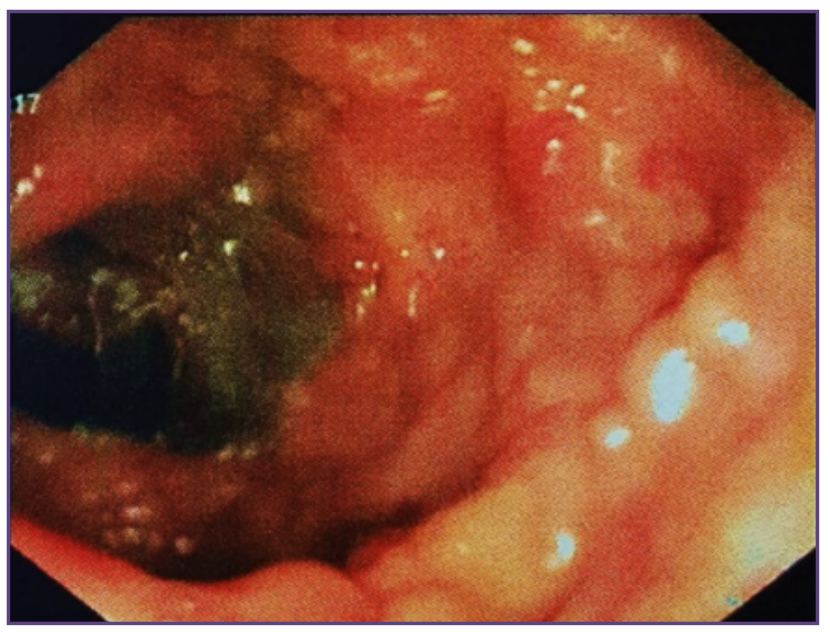

Fig. 6: Colonoscopic image from a case of ulcerative colitis showing multiple pseudopolyps in descending colon. 


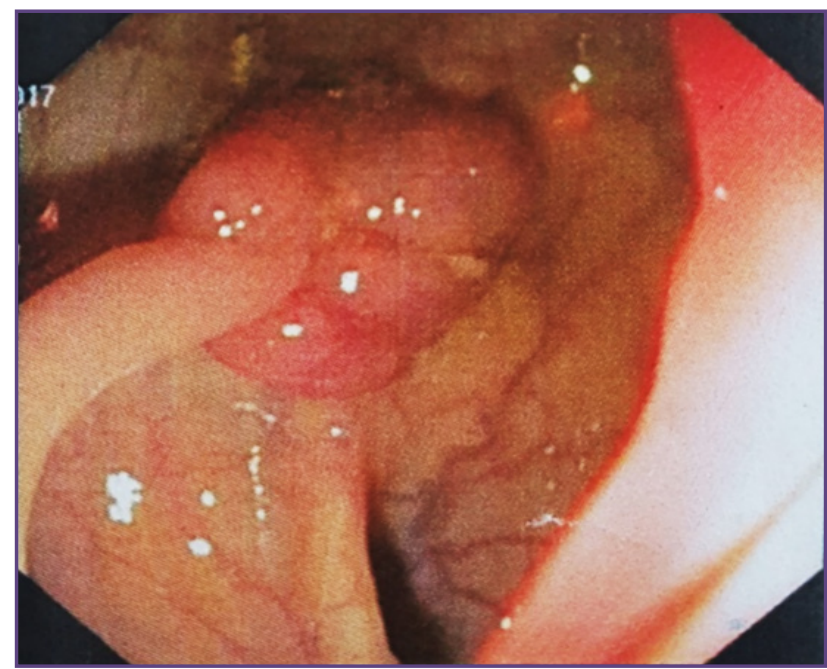

Fig. 5: Photomicrograph of Signet Ring Carcinoma (H\&E; 4X).

\section{Discussion}

Non-Neoplastic lesions: In the present study, among the non-neoplastic lesions, nonspecific colitis was found to be commonest lesion seen in 71 cases $(46.71 \%)$, studies done by Deshpande $\mathrm{V}$ etal, ${ }^{[7]}$ Rajbhanderr $\mathrm{M}$ etal ${ }^{[8]}$ and shefali $\mathrm{H}$ leave et al ${ }^{[9]}$ showed the same findings.

Ulcerative colitis though rare is an emerging disease in India, this condition portrays remissions and relapses. ${ }^{[10]}$ In the present study ulcerative colitis was found to be the second commonest non neoplastic lesion observed in 38 cases $(25 \%)$, which is comparable with the studies done by Qayyers et al, ${ }^{[11]}$ Shama VK et $\mathrm{al}^{\left[{ }^{12]}\right.}$ and is contradictory to the findings of Rajbhandari $\mathrm{M}$ et al. ${ }^{\left[{ }^{[13}\right]}$ The prevalence rate of Ulcerative colitis was high among 20 to 40 years of age with loose stools and colicky abdominal pain being the commonest presenting symptom. These are congruent with the studies done by Megha Shukla Pandey et al, ${ }^{[14]}$ Badmapriya et al ${ }^{[15]}$ and Sood A et al. ${ }^{[16]}$ [Fig 6] Hyperplastic polyp was seen in 12 cases $(7.89 \%)$ and all these cases were in between 40 to 80 years of age, which is in agreement with the study done by Williams GT et al. ${ }^{[17]}$

Chron's disease was seen in 3 cases (1.97\%) and mean age of presentation was 29 years. Loose stools and bleeding per rectum was found to be commonest symptom. The findings are akin to the studies done by Price AB et a ${ }^{18}$ and Sood A et al. ${ }^{[19]}$

Benign Lesions: All cases of benign neoplastic lesions were diagnosed as colonic adenomas. Tubular adenoma $(86.36 \%)$ outnumbered all colonic adenomas and remaining cases $(13.64 \%)$ were tubulovillous adenoma.

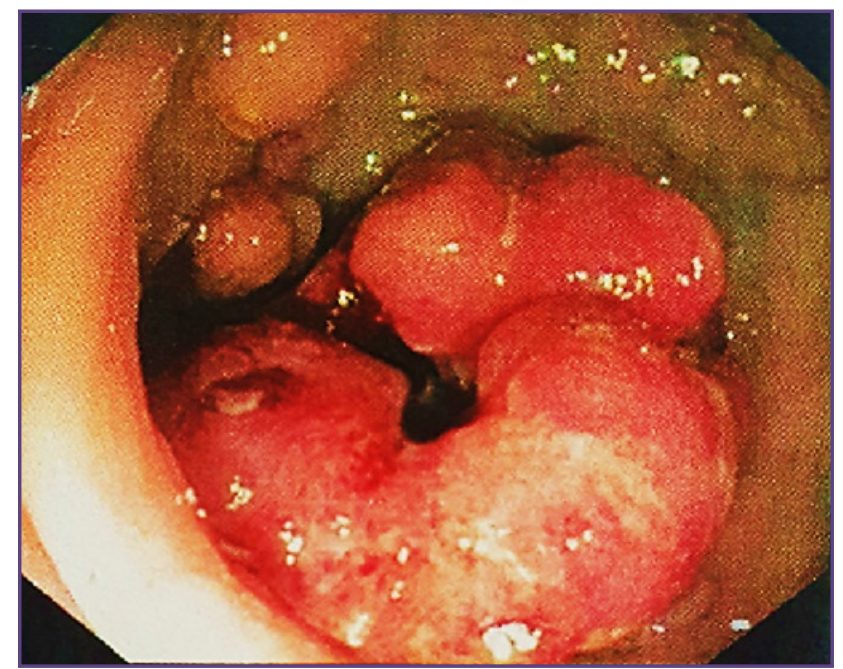

Fig. 8: Colonoscopic image showing a polypodal growth with ulceration seen at rectosigmoid region occupying $80 \%$ of lumen.

High grade dysplasia was observed in $13.63 \%$ of colorectal polyp. Study done by Konishi Fet al ${ }^{[20]}$ also showed similar findings.

Colonic Adenomas were common in the age range of $50-$ 80 years and the commonest site of occurrence was Rectosigmoid region. The M: F ratio was found to be 2.4:1. These findings were similar to the studies done by Tony $\mathrm{J}$ et $\mathrm{al}^{[21]}$ and Ritesh sulegaon et al. ${ }^{[22]}$ [Fig 7]

Malignant Lesions: In the present study, all malignant lesions were diagnosed as adenocarcinoma. Majority of the cases presented with bleeding per rectum $(80.24 \%)$ followed by abdominal pain (10.13\%) and constipation $(9.63 \%)$. Rectum being the most common site of occurrence of adenocarcinoma followed by sigmoid colon. These findings were in concordance with other studies by Yawe KT et al, ${ }^{[23]}$ Saidi HS et al ${ }^{[24]}$ and Gurjeet K et al. ${ }^{[29]}$

Maximum number of cases $(53.7 \%)$ were observed in the age group of $60-80$ years and about $30 \%$ of cases were seen in the age group of 30-50 years, exhibiting a shift in tendency of occurrence of colorectal adenocarcinoma in younger and middle aged adults. In our study the male:female ratio was found to be 1.1:1, showing almost equal incidence among both the sexes. Studies done by Caliskan $\mathrm{C}$ et al, ${ }^{[25]}$ Rasool A et $a^{\left[{ }^{[26]}\right.}{ }^{[6 u d a r s h a n ~} \mathrm{V}$ et a ${ }^{[27]}$ and Laishram RS et a ${ }^{[28]}$ also showed similar findings. [Fig 8]

Among adenocarcinomas diagnosed in our study, the most common histological subtype was found to be well differentiated adenocarcinoma (53.7\%), followed by moderately differentiated $(38.89 \%)$ and poorly 
differentiated type (5.56\%). The findings were similar to the study done by Shyamal Kumar Halder et $\mathrm{al}^{[30]}$ and in contrast to the studies done by Laishram RS et al, ${ }^{[28]}$ Shefali. H. Karve et al, ${ }^{[9]}$ Caliskan $\mathrm{C}$ et $\mathrm{al}^{[25]}$ and Ritesh sulegaon et al. ${ }^{[22]}$

\section{Conclusion}

Large intestine is affected by a long array of non-neoplastic and neoplastic lesions. Our study unveils that, ulcerative colitis which was considered to be rare, is now on the rise in India. It was observed that there is increased incidence of colorectal carcinomas among young and middle aged adults. This study emphasize that histopathological interpretation of colonic mucosal biopsies with clinical correlation play a pivotal role in the diagnosis, management and follow up of patients with colonic lesions.

\section{Acknowledgements}

The authors acknowledge Dr. C Sheshagiri, Dean and Dr. Geetha Vasu, Professor and HOD Pathology, DM WIMS for their support and encouragement

\section{Reference}

1. Fatima A. Haggar, Robin P. Boushey. Colorectal Cancer Epidemiology: Incidence, Mortality, Survival, and Risk Factors. Clin Colon Rectal Surg 2009;22:191-197

2. Boyle P, Langman JS. ABC of colorectal cancer: Epidemiology. BMJ 2000;321(7264):805-808

3. Cappell MS, Friedel D. The role of sigmoidoscopy and colonoscopy in the diagnosis and management of lower gastrointestinal disorders: endoscopic findings, therapy and complication. Med Clin North Am 2002 Nov;86:1253-88

4. Greene FL, Livstone EM, Troncale FJ. The role of fibreoptic colonoscopy in the diagnosis of colonic and rectal diseases. Comm Med.1973;37:439-42.

5. Chutkan RK, Waye JD. Endoscopy in Inflammatory bowel disease. In: KirsnerJB,ed. Inflammatory bowel disease.5th ed. Baltimare : Williams \& Wilkins:2000:453-777

6. Siddique I, Mohan K, Hasan F, Memon A,Patty I, Al-Nakib B. Appropriateness of indication and diagnostic yield of colonoscopy : First report based on the 2000 guidelines of the American Society for Gastrointestinal Endoscopy. World J Gastroenterol 2005;11(44):7007-13.

7. Deshpande V, Hsu M, Kumarasinghe MP, et al. The clinical significance of incidental chronic colitis: a study of 17 cases. Am J SurgPathol 2010; 34(4):463-9.

8. Gill MK, Jain K, Manjari M, Kaur T. Expression of Her2/neu in Colon Carcinoma and Its Correlation with the Histological Grades and the Lymph nodes status. Journal of Clinical and Diagnostic Research.2011 December, Vol-5(8): 1564-68.
9. Karve SH, Vidya K, Shivarudrappa A.S et al. The Spectrum of colonic lesions: A Clinico-pathological study of colonic biopsies. Indian Journal of Pathology and Oncology, October - December 2015;2(4);189-209

10. Azad S, Sood N, Sood A. Biological and Histological Parameters as Predictors of Relapse in Ulcerative colitis: A prospective study. Saudi J Gastroenteral 2011 MayJan;17(3): 194-198.

11. Qayyum SA, Sawan SA. Profile of colonic Biopsies in King Abdul Aziz University Hospital, Jeddah. J Pak Med Assoc 2009;59(9):608-11.

12. Paudel SMR, Sharma VK. Ulcerative colitis- is it the clinical problem in Nepal? PMJN.2007;7(2):1-6.

13. Rajbhandari M, Karmacharya A, Khanal K, Dhakal P, Shrestha R. Histomorphological Profile of Colonoscopic Biopsies and Pattern of Colorectal Carcinoma in Kavre District. Kathmandu Univ Med J 2013;43(3):196-200.

14. Pandey MS, Pandey A et al. Histomorphological Profile of Colonoscopic Biopsies - A Two Year Study in a Tertiary Care Hospital in South India. International Journal of Science and Research (IJSR). 2016;5 (2): 1513-18

15. Badmapriya D, Kumar VS. Profile of Ulcerative colitis in South India Region: Karaikal. IJPBS 2011;1(2):47-51

16. Sood A, Vandana M, et al. Profile of Ulcerative Colitis in a North India Hospital. Journal of Indian Academy of Clinical Medicine 1998; 5(2):124-128.

17. Williams GT, Arthur JF, Bussey HJ, Morson BC. Metaplastic polyps and polyposis of the colorectum. Histopathology.1980;4(2):155-70.

18. Price $\mathrm{AB}$, Morson BC. Inflammatory bowel disease: The surgical pathology of Crohn's disease and ulcerative colitis. Hum Pathol.1975;6(1):7-29.

19. Sood A, Midha V, Sood N, Bhatia AS, Avasthi G. Incidence and prevalence of ulcerative colitis in Punjab, North India. Gut. 2003;52(11):1587-90.

20. Konishi F, Morson BC. Pathology of colorectal adenomas. A colonoscopic survey. J Clin Pathol. 1982;35(8): 830-41.

21. Tony J, Harish K, Ramachandran TM, Sunilkumar K, Thomas V. Profile of colonic polyps in a southern Indian population. Indian J Gastroenterol. 2007;26(3):127-29.

22. Sulegaon R, Shete S, Kulkarni D. Histological Spectrum of Large Intestinal Lesions with Clinicopathological Correlation. Journal of Clinical and Diagnostic Research. 2015,9(11): EC30-EC34

23. Yawe KT, Bakeri AA, Pindiga UH, et al. Clinicopathological pattern and challenges in the management of colorectal cancer in sub-saharan Africa. J Chinese Clin Med 2007;2:688-95.

24. Saidi HS, Karuri D, Nyaim EO: Correlation of clinical data, anatomical site and discuss stage in colorectal cancer. East Afr Med J:2008;85:259-62. 
25. Caliskan C, Guler N, Karaca C, Makay O, Firat O, Korkut MA. Negativeprognostic factors in colorectal carcinoma: an analysis of 448 patients.Indian J Surg. 2010;72:243-48.

26. Rasool A, Bari S, Rashid S, Wani AH, Wani RA, Peer GQ. Outcome of patients with acute intestinal obstruction due to colorectal carcinoma. The internet journal of surgery. 2009;20(1).

27. Sudarshan V, Hussain N, Gahine R, Mourya J. Colorectal cancer in young adults in a tertiary care hospital in Chattisgarh, Raipur. Indian Journal of Cancer, 2013; 50(4): 337-40.
28. Laishram RS, Kaiho N, Shimray R, Devi SB, Punyabati P, Sharma DC. Histopathological Evaluation of Colorectal Carcinomas status in Manipur, India. International Journal of Pathology:2010; 8(1):5-8.

29. Gurjeet K, Abdelhafid M, et al. Mismatch repair genes expression defects \& association with clinicopathological characteristics in colorectal carcinoma. Indian J Med Res 2011;134(2):186-192.

30. Shyamal Kumar Halder et al. Epidemiological, ClinicoPathological Profile and Management of Colorectal Carcinoma in a Tertiary Referral Center of Eastern India. JKIMSU, 2013; 2(1):45-50.

*Corresponding author:

Abilash S C, Associate Professor Pathology, DM Wayand Institute of Medical Sciences, Naseera Nagar, Meppadi, Wayanad, Kerala India 673577

Phone: +919894346193

Email: abey4aris@gmail.com

Date of Submission : 01.06.2017

Date of Acceptance : 30.06.2017

Financial or other Competing Interests: None.

Date of Publication : 26.10.2017 